\title{
RP-HPLC-UV Analysis of the Phenolic Compounds, Antimicrobial Activity Against Multi-Drug Resistant Bacteria and Antioxidant Activity of Fruit and Seed of Diospyros lotus L.
}

\section{Zeynep Akar ${ }^{(1, *}$, Aylin Karakurt ${ }^{(2)}$, Funda Okumus ${ }^{(D 2}$, Sedanur Cinemre ${ }^{\left(D^{2}\right.}$, Azer Ozad Duzgun ${ }^{10}$, Bulent Akar ${ }^{(1)}$, Zehra Can 5}

\author{
${ }^{1}$ Department of Genetics and Bioengineering, Faculty of Engineering and Natural Sciences, Gümüşhane \\ University, Gümüşhane, Turkey \\ ${ }^{2}$ Department of Biotechnology, Institute of Natural Sciences, Gümüşhane University, Gümüşhane, Turkey \\ ${ }^{3}$ Medicinal Plants, Traditional Medicine Practice and Research Center, Gümüşhane University, Gümüşhane, \\ Turkey \\ ${ }^{4}$ Department of Food Engineering, Faculty of Engineering and Natural Sciences, Gümüşhane Universty, \\ Gümüşhane, Turkey \\ ${ }^{5}$ Department of Emergency and Disaster Management School of Applied Sciences, Bayburt University, Bayburt, \\ Turkey
}

\begin{abstract}
The object of the present study was to investigate the antioxidant, antimicrobial activity and phenolic compounds of fruit and seeds of Diospyros lotus L. The fruits consumed by humans as nutrients were harvested from the plants that grow naturally in the province of Trabzon-Akçaabat, Eastern Black Sea Region of Turkey. The antioxidant activities of fruit and seeds of Diospyros lotus were determined by using four methods (\% DPPH radical scavenging activity, FRAP antioxidant power determination, CUPRAC reducing antioxidant activity and total phenolic content (TPC) in five different proportion of methanol-water extracts. All extracts of fruit and seeds of D. lotus analyzed through whole antioxidant analysis methods showed significant antioxidant activity. In addition, antimicrobial activity of fruit and seeds extracted with DMSO was determined against seven standard bacteria and three multi-drug resistance clinical strains. Although fruit extracts did not have the antimicrobial activity against bacteria, seeds showed antimicrobial effect to both standard strains (Gram-negative and Gram-positive) and antibiotic resistance clinical isolates (Klebsiella pneumoniae carrying bla ${ }_{\mathrm{KPC}}$, Acinetobacter baumannii, harboring bla OXA-23 $_{\text {gene and resistance to colistin, and multi-drug resistant }}$ Pseudomonas aeruginosa). MICs' value of plant seed extracts for standard strains was $0.75-25 \mathrm{mg} / \mathrm{mL}$ and antibiotic resistant clinical bacteria were 12.5 and $25 \mathrm{mg} / \mathrm{mL}$. Additionally, phenolic compounds in methanol extracts of fruit and seeds were also determined in by HPLC using 19 standards. Gallic acid and chrysin phenolic compounds were the major phenolic compounds in fruit and seeds, respectively.
\end{abstract}

\section{ARTICLE HISTORY}

Received: April 03, 2020

Revised: July 03, 2020

Accepted: November 06, 2020

\section{KEYWORDS}

Antioxidant,

Diospyros lotus,

Multi-drug Resistant

Bacteria,

Phenolic Compounds

CONTACT: Zeynep AKAR $₫$ zeynep_iskefiyeli@hotmail.com Đ Department of Genetics and Bioengineering, Faculty of Engineering and Natural Sciences, Gümüşhane University, Gümüşhane, Turkey 


\section{INTRODUCTION}

While organisms continue their cellular metabolic functions in the usual way, at the same time, the oxygen required for aerobic respiration, which is one of the elements of usual metabolic functions, can cause serious cell damage during oxidation. In other words, oxygen in the cell can produce reactive oxygen species (ROS) that occurs free radicals, while it produces energy with oxidative phosphorylation [1]. Increased production of ROS causes oxidative stress that is the cause of many diseases such as diabetes, cancer, epilepsy, cardiovascular conditions and inflammatory diseases [2,3]. For example, in 2018 year, new cancer cases of 18.1 million were detected in the world, 9.6 million of which resulted in death [4]. There are antioxidant defense systems in order to halt the progression of these diseases in the body. The antioxidants effect chain reactions with free radicals that occur in the cell for various reasons and damage the cell and affect the that they initiate. Antioxidants, one of the components of the defense system, react with free radicals and affect the formation of chain reactions the excess in diseases caused by free radicals the increased the tendency towards natural foods with strong antioxidant properties [5,6].

Not only free radicals but also infections show a significant effect on the development of some diseases in humans and animals. Especially infections were started to be controlled with the exploration of antibiotics in the later 19th century and early 20th century. For 60 years, antibacterial drugs have been considered a panacea to cure infections and have been used extensively regardless of the source and type of infection. In addition, misuse of antibiotics, such as skipping dose, overuse and low dose antibiotic intake, has potentially promoted antibiotic resistance to the bacteria rather than eliminating the infection [7-11]. The type of infection has become a life-threatening problem. Therefore, in recent times, interest has been raised to the researches for the development of new antimicrobial substances from various organisms to combat antibiotic resistance. Although new antibiotics against bacteria are commonly obtained from prokaryotic organisms (bacteria) and some eukaryotic organisms (microorganisms, plants, and various animals); especially microorganisms and plants are the main source of them [12]. Secondary metabolites obtained from plants exhibit antimicrobial effect as well as some pharmacological effects (antioxidative, anticancer and anti-inflammatory activities and prevent coronary heart disease, anti-atherosclerotic and hepatoprotective) on human health $[10,13]$. The usage of plants in the cure of various diseases has a long history. Up to the present time, 35000-70000 species of plant have been screened for medical use. Particularly, plants with ethnopharmacological have been the main sources for drug discovery [14]. Among these plants, Diospyros lotus L. fruits are used in traditional medicine but also consumed as food. The fruits are used as antiseptic, antitumor, astringent, antidiabetic and in treating diarrhea, dry cough, febrifuge, hypertension [15]. In addition, its seeds show sedative effect [16].

Diospyros genus in the Ebanaceae family contains approximately 200 species. D. lotus is one of the four species that have a pomological value among these species. The species is a deciduous tree and its maximum heights $15 \mathrm{~m}$. It spreads naturally in the Northeast and South regions of Turkey. The fruit is a globose shape which is about from 1.5 to $2.0 \mathrm{~cm}$ in diameter and immature and ripe fruits are yellow and bluish-black color, respectively [17-19]. Some studies were performed to determine both the biological activities and the chemical composition of the D. lotus [15,16,20-24]. In addition, although there are some studies on the biological activity [25] and chemical composition of D. lotus collected from Turkey [17,26-29], any studies have not been conducted to determine the antimicrobial activity against multi-drug resistant bacteria and antioxidant activity of the fruit and seed portion of D. lotus.

Fruit and seed of D. lotus grown in Turkey's Eastern Black Sea Region in the present study were aimed to determine the antioxidant activity with different methods and antimicrobial 
activity against three Gram-positive, four Gram-negative bacterial strains and three multi-drug resistant bacteria. Also it was determined that the chemical composition of the fruit and seed.

\section{MATERIAL and METHODS}

\subsection{Chemicals and Reagents}

The chemicals and reagents used in the study were obtained from various companies, for example; Trolox ${ }^{\circledR}, 2,4,6$-tripyridyl-s-triazine (TPTZ), 2,2-diphenyl-1-picrylhydrazyl (DPPH•), 2,9-dimethyl-1,10-phenanthroline (neocuproine), anhydrous iron (III) chloride $\left(\mathrm{FeCl}_{3}\right)$ were purchased from Sigma-Aldrich. Copper (II) chloride $\left(\mathrm{CuCl}_{2}\right)$, acetic acid $(\geq 99.8 \%$ ), ammonium acetate, HPLC grade methanol ( $\geq 99.9 \%)$ and ethanol ( $\geq 99.5 \%)$, were supplied from Merck. Folin-Ciocalteu reactive and HPLC standards Sigma-Aldrich, HPLC Elite LaChrom Hitachi, Japan. Evaporator IKA-Werke, Staufen, Germany. Syringe filter RC-membrane, $0.45 \mu \mathrm{m}$.

\subsection{Preparation of Plant Extraction}

The fruits of the D. lotus were harvested in the Akçaabat district of Trabzon province in December 2017. The seeds (S) from fruit (F) of the plant were separated and both fruit and seeds are dried at room temperature. The dried fruits and seeds are milled in Waring Commercial Blender device.10 $\mathrm{g}$ of fruit powder and seed powder were weighed, separately and extracted in five different percentages of $100 \mathrm{~mL}$ methanol-pure water solutions (Table 1).

Thus, the extracts were mixed with a magnetic stirrer for 2 hours and were successively filtered through Whatman filter papers to obtain clear solutions. The extracts were stored in a cool, dark place at room temperature until analysis. In addition, in order to determine the antimicrobial activity, DMSO extracts were prepared for both fruits and seeds as in preparation of methanol-water extracts.

Table 1. Solvent ratios for fruit and seed extraction

\begin{tabular}{cccccc}
\hline Fruit Samples & \% Methanol & \% Water & Seed Samples & \% Methanol & \% Water \\
\hline F1 & 100 & - & S1 & 100 & - \\
F2 & 75 & 25 & S2 & 75 & 25 \\
F3 & 50 & 50 & S3 & 50 & 50 \\
F4 & 25 & 75 & S4 & 25 & 75 \\
F5 & - & 100 & S5 & - & 100 \\
\hline
\end{tabular}

\subsection{Plant Extraction for HPLC}

Solvents of the methanol extracts of the fruit and seeds of the plant were evaporated with a rotary evaporator device at $40^{\circ} \mathrm{C}$. The residue dissolved in $10 \mathrm{~mL} \mathrm{pH} 2$ water was extracted, for the phenolic compounds, three times with $15 \mathrm{~mL}$ of diethyl ether then, three times with 15 $\mathrm{mL}$ of ethyl acetate consecutively. Organic phase was picked up in the same flask and evaporated till drying under reduced pressure in a rotary evaporator at $40^{\circ} \mathrm{C}$. Then the residues were weighed and dissolved with $2 \mathrm{~mL}$ of methanol for HPLC analysis. This solution was filtered with $0.45 \mu \mathrm{m}$ Whatman nylon filter and analyzed by HPLC-UV [30].

\subsection{Determination of Antioxidant Activity}

\subsubsection{DPPH Radical Scavenging Activity}

DPPH radical cleaning test is one of the most preferred methods in the determination of the antioxidant activity of the substances. The method developed by Cuendet et al. [31] was modified and applied to extracts. Firstly, a $100 \mu \mathrm{M}$ methanolic DPPH• solution was mixed in the magnetic stirrer for $30 \mathrm{~min}$ and then a DPPH• reagent solution was prepared. Both the sample mixture and the reagent blank 3 were run in parallel. After $50 \mathrm{~min}$, the absorbance values 
of the tubes mixed with DPPH reagent were determined at $517 \mathrm{~nm}$ and $\%$ inhibition (DPPH• cleaning) values were calculated using the following formula.

$\%$ Inhibition (radical cleaning power $)=\left[\left(\mathrm{A}_{\mathrm{DPPH}}-\mathrm{A}_{\text {Sample }}\right) / \mathrm{A}_{\mathrm{DPPH}}\right] \mathrm{X} 100$

ADPPH : Absorbance value of the DPPH solution

Asample: Absorbance value of the sample extract

\subsubsection{Ferric Reducing Antioxidant Power (FRAP)}

The antioxidant assay method was based on the principle of measuring the absorbance of the $\mathrm{Fe}^{2+}$-TPTZ (2,4,6-tris (2-pyridyl) -s-triazine complex in $595 \mathrm{~nm}$ [32]. The FRAP reagent consists of mixture of $10 \mathrm{mM}$ TPTZ in $40 \mathrm{mM} \mathrm{HCl}$ and $20 \mathrm{mM} \mathrm{FeCl}_{3} \cdot 6 \mathrm{H}_{2} \mathrm{O}$ and $300 \mathrm{mM}$ acetate buffer ( $\mathrm{pH}$ 3.6), in 1:1:10 ratio respectively. The calibration curve was created using the Trolox standard in different volumes (1000-500-250-125-62.5 $\mu \mathrm{M}) .50 \mu \mathrm{L}$ of the plant extracts and standard Trolox solutions were vortexed with FRAP reagent $(1.5 \mathrm{~mL})$ and were kept at room temperature for 20 minutes. Then the values of absorbance were read at $595 \mathrm{~nm}$ against pure water. In addition, the absorbance of reagents and sample blanks was measured and these values were subtracted from the mean values of the three studied parallel samples. Antioxidant activity of FRAP was calculated based on Trolox calibration graph and expressed as TEAC, $\mu \mathrm{M}$ (Trolox equivalent antioxidant capacity). In the evaluation of the results, the high TEAC values of the samples also indicate high FRAP and therefore high antioxidant capacity.

\subsubsection{Cupric Reducing Antioxidant Capacity (CUPRAC)}

In CUPRAC method, 2,9-dimethyl-1,10-phenanthroline (Neocuproine-Nc) was used with $\mathrm{Cu}$ (II) to form Copper (II) -neocuproine complex [Cu (II) -Nc] [33]. The antioxidant capacity was determined with the reduction of the $\mathrm{Cu}(\mathrm{II})-\mathrm{Nc}$ to $\mathrm{Cu}(\mathrm{I})-\mathrm{Nc}$ chelate that has maximum absorbance at $450 \mathrm{~nm}[33]$. Antioxidant standard Trolox ${ }^{\circledR}$ was studied at six different concentrations $(0.03125-0.625-0.125-0.25-0.5-1-\mathrm{mg} / \mathrm{mL})$ for plotting calibration curve. After pipetting, tubes were vortexed and kept in darkness for 30 minutes. Absorbance values of the solutions in each tubes transferred to plastic cuvettes were read at 450 nanometers. The results were compared with Trolox ${ }^{\circledR}$, a standard antioxidant with a high reduction potential and were expressed as Trolox ${ }^{\circledR}$ equivalent antioxidant capacity ( $\mu \mathrm{M}$ TEAC).

\subsubsection{Total Phenolic Content (TPC)}

The total phenolic content of the fruit and seed of the $D$. lotus was determined by modified Slinkard and Singleton [34]. method with use of Folin-Ciocalteu reagent. Firstly, $50 \mu \mathrm{L}$ of the sample solution was diluted with $2.5 \mathrm{~mL}$ of distilled water, then $250 \mu \mathrm{L}$ of $0.2 \mathrm{~N}$ FolinCiocalteu reagent and $750 \mu \mathrm{L}$ of $\mathrm{Na}_{2} \mathrm{CO}_{3}(7.5 \%)$ was added and vortexed. The prepared tubes were incubated for 2 hours at room temperature and the absorbance values at $765 \mathrm{~nm}$ were determined. The amount of phenolic compounds in the samples was determined based on function of the line obtained from calibration graph of gallic acid standart (1000-500-150-125$62.5 \mu \mathrm{g} / \mathrm{mL})$ in six different concentrations as gallic acid equivalent $(\mathrm{GAE}(\mu \mathrm{g} / \mathrm{mL}))$.

\subsection{Analysis of Phenolic Compounds by HPLC}

The phenolic contents of the methanol extracts of the fruits and seed of D. lotus were determined by using the Elite LAChrom Hitachi, Japan HPLC with a UV-Vis detector. In total, nineteen of phenolic compounds standards (caffeic acid, catechin, chrysin, daidzein, epicatechin, ferulic acid, gallic acid, hesperetin, luteolin, myricetin, $p$-coumaric acid, 4hydroxybenzoic acid, pinocembrin, protocatechuic acid, resveratrol, rutin, syringic acid, $t$ cinnamic acid and CAPE (caffeic acid phenethyl ester)) were used. The extracts were injected into an inverted phase $\mathrm{C} 18$ column (150 mm x $4.6 \mathrm{~mm}, 5 \mu \mathrm{m}$; Fortis). The mobile phase was formed within mixing of solvents $\mathrm{A}(2 \% \mathrm{AcOH}$ in water) and $\mathrm{B}$ (acetonitrile/water in 70:30 ratio) which was sonicated before stirring and continuously degassed by the built-in HPLC 
system. The temperature of the column was fixed at $30^{\circ} \mathrm{C}$ and $20 \mu \mathrm{L}$ of extracts were injected. The mobile phase was composed of water $(2 \% \mathrm{AcOH})$ and acetonitrile/water (70:30) filtered using a $0.45 \mu \mathrm{m}$ nylon filter (Whatman, Maidstone, The United Kingdom) degassed in a sonicator for $30 \mathrm{~min}$. The mobile phase flow rate was $0.75 \mathrm{~mL} / \mathrm{min}$, and the elution in the gradient mode occurred as follow: 0 min $5 \% \mathrm{~B}$ in $\mathrm{A} ; 8$ min $15 \% \mathrm{~B}$ in $\mathrm{A} ; 10 \min 20 \% \mathrm{~B}$ in $\mathrm{A}$; $12 \min 25 \% \mathrm{~B}$ in $\mathrm{A} ; 20 \mathrm{~min} 40 \% \mathrm{~B}$ in $\mathrm{A} ; 30 \min 80 \% \mathrm{~B}$ in $\mathrm{A} ; 35 \min 5 \% \mathrm{~B}$ in $\mathrm{A} ; 50 \min 5 \% \mathrm{~B}$ in A. Phenolic profile was determined according to Can et al. [30].

\subsection{Determination of Minimum Inhibition Concentration}

The minimum inhibitory concentration (MIC) of the plant extract against to 3 Grampositive (Bacillus subtilis ATCC 6633, Streptococcus pyogenes ATCC 19615 and Staphylococcus aureus ATCC 25923) and 4 Gram-negative bacterial strains (Escherichia coli ATCC 25922, Proteus vulgaris ATCC 13315, Pseudomonas aeruginosa ATCC 43288, Yersinia pseudotuberculosis ATCC 911) and antibiotic resistant strains (Acinetobacter baumannii, E. coli, Klebsiella pneumoniae, and Pseudomonas aeruginosa) were determined with the use of the liquid microdilution method. DMSO was used as a solvent for extracts. The extracts concentration are $100 \mathrm{mg} / \mathrm{mL}$ (serial two-fold dilution was carried out) obtained from the fruit and seed of the plant. Ampicillin used as control. MIC values of the DMSO fruit and seed extracts were determined in the 96-well plates and triplicate.

\section{RESULTS and DISCUSSION}

\subsection{Antioxidant Activity of D. lotus Extract}

The antioxidant activities of fruits and seeds of D. lotus plant were investigated by using four different antioxidant determination methods in methanol-water extracts at different percentages. In the DPPH radical scavenging method, while F1 (100\% methanol) had the highest antioxidant activity value with 79.04 and the lowest activity was measured as 59.94 for F4 sample (25\% methanol- $75 \%$ water (Table 2). In the extracts of the seeds, the highest antioxidant activity was measured as 85.63 in S1 extract (100\% methanol) as in fruits. However, the lowest activity was determined with 64.17 in S2 extract (75\% methanol- 25\% water) (Table 2).

Table 2. The antioxidant activities of methanol and water extracts in different percentage of fruits and seeds of $D$. lotus plant

\begin{tabular}{ccccc}
\hline Samples & TPC $(\mathrm{GAE} \mu \mathrm{g} / \mathrm{mL})$ & FRAP $(\mu \mathrm{M}$ TEAC $)$ & CUPRAC $(\mu \mathrm{M}$ TEAC $)$ & DPPH $(\%)$ \\
\hline F1 & $416.51 \pm 0.05$ & $250.00 \pm 0.01$ & $0.05 \pm 0.06$ & $79.04 \pm 0.05$ \\
F2 & $306.82 \pm 0.01$ & $347.60 \pm 0.03$ & $0.04 \pm 0.01$ & $72.24 \pm 0.07$ \\
F3 & $289.82 \pm 0.11$ & $163.60 \pm 0.10$ & $0.03 \pm 0.01$ & $66.44 \pm 0.08$ \\
F4 & $124.12 \pm 0.08$ & $43.64 \pm 0.01$ & $0.02 \pm 0.07$ & $59.94 \pm 0.10$ \\
F5 & $105.91 \pm 0.01$ & $7.270 \pm 0.02$ & $0.01 \pm 0.01$ & $66.54 \pm 0.08$ \\
S1 & $569.81 \pm 0.03$ & $190.60 \pm 0.02$ & $0.27 \pm 0.02$ & $85.63 \pm 0.04$ \\
S2 & $659.80 \pm 0.04$ & $471.50 \pm 0.05$ & $0.58 \pm 0.06$ & $64.17 \pm 0.09$ \\
S3 & $632.61 \pm 0.01$ & $215.51 \pm 0.12$ & $0.32 \pm 0.02$ & $69.78 \pm 0.07$ \\
S4 & $521.00 \pm 0.10$ & $71.82 \pm 0.03$ & $0.22 \pm 0.02$ & $70.77 \pm 0.07$ \\
\hline
\end{tabular}

*Different letters in the same column indicate significantly different at the $5 \%$ level $(\mathrm{p}<0.05)$ among the results.

Similar results were obtained in FRAP, CUPRAC and TPC antioxidant detection methods. In all three methods, F2 (75\% methanol- $25 \%)$ and F5 (100\% water) showed the highest and lowest antioxidant activity respectively for both seed extracts and fruit extracts. It 
was determined that the antioxidant activity of the seed extracts was higher than the fruit extracts in all antioxidant determination methods.

In addition, the antioxidant activity of the extracts, which are generally $100 \%$ water in the solvent, was found to be lower than the others. Except for the DPPH test, antioxidant activity was higher in fruits and seeds in $75 \%$ methanol- $25 \%$ water and $50 \%$ methanol- $50 \%$ water extracts for all three methods. In some studies conducted to determine DPPH radical scavenging activity values of $D$. lotus plant fruits (methanolic extract) grown in different regions of the world, determined values were significant [20,21,23]. Moreover, Lozzio et al. [20] also found high antioxidant activity using FRAP and ABTS methods.

\subsection{Phenolic Compounds in D. lotus Extract}

While five phenolic acids; gallic acid $>$ ferulic acid >protocatechuic acid $>$ syringic acid $>t$-cinnamic acid were determined in methanolic fruit extract (Table 3) eight phenolic compound; gallic acid $>$ chrysin $>$ CAPE $>$ catechin $>$ caffeic acid $>p$-coumaric acid $>$ protocateuic acid $>t$-cinnamic acid were identified in the seed extract (Table 3). It was observed that the seed parts were richer in terms of phenolic content as well as antioxidant activity. The results support the antioxidant results. As it is seen in the Table 3, gallic acid, protocatechuic acid and $t$ cinnamic acid were present in both fruit and seed. While gallic acid was measured in the highest quantity with $234.74 \mu \mathrm{g} / \mathrm{g}$ in fruit extract and it was second with $1065.54 \mu \mathrm{g} / \mathrm{g}$ in seed extract among the determined phenolic compounds. However, although the chrysin and CAPE was not present in fruit extracts, they reached quantitatively highest abundance with 1086.09 and 768.2 $\mu \mathrm{g} / \mathrm{g}$ in seed extract respectively.

Table 3. HPLC analysis of phenolic composition of D. lotus

\begin{tabular}{lcc}
\hline HPLC standards & Fruit $(\mu \mathrm{g}$ extract/g) & Seed $(\mu \mathrm{g}$ extract/g) \\
\hline Gallic acid & 234.7 & 1066 \\
Protocatechuic acid & 28.13 & 44.43 \\
4-hydroxybenzoic acid & nd & nd \\
Catechin & nd & 343.2 \\
Caffeic acid & nd & 121.4 \\
Syringic acid & 15.53 & nd \\
Epicatechin & nd & nd \\
$p$-coumaric acid & nd & 68.27 \\
Ferulic acid & 48.44 & nd \\
Rutin & nd & nd \\
Myricetin & nd & nd \\
Resveratrol & nd & nd \\
Daidzein & nd & nd \\
Luteolin & nd & nd \\
$t$-cinnamic acid & 6.36 & 21.42 \\
Hesperetin & nd & nd \\
Chrysin & nd & 1087 \\
Pinocembrin & nd & nd \\
CAPE & nd & 768.2 \\
\hline
\end{tabular}

nd: non detected

Ayaz et al. [27] searched phenolic content of D. lotus fruits at different times during the development period of fruit in GC-MS and reported that eight phenolic acids (salicylic acid, 4hydroxybenzoic acid, vanillic acid, gentistic acid, 3,4-dihydroxybenzoic acid, syringic acid, $p$ coumaric acid, gallic acid). Gallic acid and syringic acid were also detected and gallic acid showed the highest amount the same as our study. Gao et al. [16] also used ten phenolic acid standards in HPLC analysis of phenolic compounds in different extracts of D. lotus. Seven of 
these standards (caffeic acid, ferulic acid, gallic acid, myricetin, p-coumaric acid, protocatechuic acid and rutin) were common with the present study. Similarly, rutin was not detected, while gallic acid was detected in the highest abundance [16]. Gallic acid, a phenolic compound of plant origin, is a powerful antioxidant [35]. In addition, it also shows the effects of antimutagenic, antitumor, antibacterial anti-inflammatory [35,36]. Rashed et al. [24] reported that among seven phenolic compounds obtained from $D$. lotus fruits, gallic acid was the most active compound against HIV-1 and inhibited HIV-1 $1_{\text {IIIB }}$ replication with $\mathrm{EC}_{50}$ value of 6.09 $\mu \mathrm{g} / \mathrm{mL}$. Again, the plant phenolic compounds were used against human cancer cells and gallic acid exhibit the highest anticarcinogenic effect against colorectal adenocarcinoma (IC50 2.6 $\mu \mathrm{g} / \mathrm{mL}$ ) and lung large cell carcinoma (IC50 $4.66 \mu \mathrm{g} / \mathrm{mL}$ ) [20]. Moghaddam et al. [23] conducted a study on the seed of this plant to determine its biological activity. However, the phenolic content of seed has not been studied. Although chrysin was present in some plants, honey, and propolis [37] it was first detected in the D. lotus plant in this study. It was also measured at the highest level among the identified phenolics in the seed. Chrysin is an important natural flavonoid having many biological activities such as aromatase inhibitor, antioxidant, anti-cancer, antiviral activities and anti-inflammatory effects [38,39].

\subsection{Antimicrobial Activity}

DMSO extract of plant seed has inhibited the growth of studied bacteria but DMSO extract of plant fruit did not have antimicrobial activity against bacteria. MICs of plant seed extracts were found to be between $0.75-25 \mathrm{mg} / \mathrm{mL}$. Extract of plant seed showed very potent activity against $E$. coli and $S$. pyogenes with $0.75 \mathrm{mg} / \mathrm{mL}$ MIC. MIC values of plant seed extract for Bacillus subtilis and P. aeruginosa were $12.5 \mathrm{mg} / \mathrm{mL}$. Also, it was determined that the DMSO extract of plant seed had a lower MIC value $(25 \mathrm{mg} / \mathrm{mL})$ against $S$. aureus, $Y$. pseudotuberculosis and Proteus vulgaris. MIC values of plant extract against antibiotic resistant clinical bacteria were 12.5 and $25 \mathrm{mg} / \mathrm{mL}$. DMSO extract of the plant seed was determined to be the highest MIC $(12.5 \mathrm{mg} / \mathrm{mL})$ against $K$. pneumonae carrying bla $a_{\mathrm{KPC}}, A$.

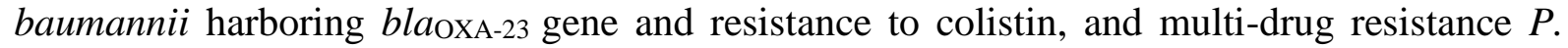
aeruginosa. MIC value of the plant seed extract was found to be $25 \mathrm{mg} / \mathrm{mL}$ against NDM type metallo beta lactamase harboring $K$. pneumonia and multi-drug resistance $E$. coli.

\section{CONCLUSION}

Methanol and water extracts in different percentages of $D$. lotus plant fruits and seeds showed antioxidant activity in all antioxidant methods. Significantly, the content of phenolic compounds in plants contributes antioxidant activity. Among the phenolic compounds detected in this study, the highest measured gallic acid (in fruit and seed) and chrysin (only seed) may be determinant antioxidant activity. Chrysin flavonoid, which has high biological activity, can be studied in more detail in both naturally grown and cultivated D. lotus seeds. Antibioticresistant strains, especially multidrug-resistant isolates, are a serious threat to public health. The spread of beta-lactamases that hydrolyze antibiotics among bacteria has become a worldwide problem. To combat antibiotic resistance, many scientists are looking for both synthetic and natural products around the world. In this study, we show the antibacterial activity of plant seed extracts against multi-drug resistant strains that cause difficulties in the clinic.

\section{Declaration of Conflicting Interests and Ethics}

The authors declare no conflict of interest. This research study complies with research publishing ethics. The scientific and legal responsibility for manuscripts published in IJSM belongs to the author(s). 


\section{Orcid}

Zeynep Akar (D) https://orcid.org/0000-0001-9262-8070

Aylin Karakurt (D) https://orcid.org/0000-0002-4755-6669

Funda Okumus ${ }^{(D)}$ https://orcid.org/0000-0002-2494-7050

Sedanur Cinemre (iD https://orcid.org/0000-0001-9556-9678

Azer Ozad Düzgün (D) https://orcid.org/0000-0002-6301-611X

Bülent Akar (iD https://orcid.org/0000-0002-1421-374X

Zehra Can (D) https://orcid.org/0000-0002-7156-4941

\section{REFERENCES}

[1]. Halliwell, B., Gutteridge J.M.C. (1990). Role of Free Radicals and Catalytic Metal Ions in Human Disease: An Overview. Method Enzymol., 186, 1-85. https://doi.org/10.1016/0076-6879(90)86093-b

[2]. Panayiotidis, M. (2008). Reactive Oxygen Species (ROS) in Multistage Carcinogenesis. Cancer Lett., 266(1), 3-5. https://doi.org/10.1016/j.canlet.2008.02.027

[3]. Ferlay, J., Autier, P., Boniol, M., Heanue, M., Colombet, M., Boyle, P. (2007). Estimates of the Cancer Incidence and Mortality in Europe in 2006. Ann. Oncol., 18(3), 581-592. https://doi.org/10.1093/annonc/mdl498

[4]. Ferlay, J., Colombet, M., Soerjomataram, I., Mathers, C., Parkin, D.M., Piñeros, M., Znaor, A., Bray, F. (2019). Estimating the Global Cancer Incidence and Mortality in 2018: GLOBOCAN Sources and Methods. Int. J. Cancer, 144(8), 1941-1953. https://doi.org/10.1002/ijc.31937

[5]. Ames, B.M., Shigenaga, M.K., Hagen, T.M. (1993). Oxidants, Antioxidants, and the Degenerative Diseases of Aging. P. Natl. Acad. Sci. USA., 90, 7915-7922. https://doi.org/10.1073/pnas.90.17.7915

[6]. Valle, I., Álvarez-Barrientos, A., Arza, E., Lamas, S., Monsalve, M. (2005). PGC-1 $\alpha$ Regulates the Mitochondrial Antioxidant Defense System in Vascular Endothelial Cells. Cardiovasc. Res., 66(3), 562-573. https://doi.org/10.1016/j.cardiores.2005.01.026

[7]. Li, B., Webster, T.J. (2018). Bacteria Antibiotic Resistance: New Challenges and Opportunities for Implant-Associated Orthopedic Infections. Journal of J. Orthopaed. Res., 36(1), 22-32. https://doi.org/10.1002/jor.23656

[8]. WHO (World Health Organization). (2014). Antimicrobial Resistance: Global Report on Surveillance 2014, World Health Organization: Geneva, Switzerland. ISBN: 9789241564748.

[9]. Kardas, P., Devine, S., Golembesky, A., Roberts, C. (2005). A Systematic Review and Meta-Analysis of Misuse of Antibiotic Therapies in the Community. Int. J. Antimicrob. Ag., 26(2), 106-113.

https://doi.org/10.1016/j.ijantimicag.2005.04.017

[10]. Górniak, I., Bartoszewski, R., Króliczewski, J. (2019). Comprehensive Review of Antimicrobial Activities of Plant Flavonoids. Phytochem. Rev., 18(1), 241-272. https://doi.org/10.1007/s11101-018-9591-z

[11]. Tanrıkulu, G.İ., Ertürk, Ö., Yavuz, C., Can, Z., Çakır, H.E. (2017). Chemical compositions, antioxidant and antimicrobial activities of the essential oil and extracts of Lamiaceae family (Ocimum basilicum and Thymbra spicata) from Turkey. Int. J. Second. Metab., 4(3-2), 340-348. https://doi.org/10.21448/ijsm.373828 
[12]. Balouiri, M., Sadiki, M., Ibnsouda, S.K., (2016). Methods For in Vitro Evaluating Antimicrobial Activity: A Review. J. Pharm. Anal., 6(2), 71-79. https://doi.org/10.1016/j.jpha.2015.11.005

[13]. Akar, Z., Küçük, M., Doğan, H. (2017). A New Colorimetric DPPH• Scavenging Activity Method with No Need for a Spectrophotometer Applied on Synthetic and Natural Antioxidants and Medicinal Herbs. J. Enzym Inhib. Med. Ch., 32(1), 640-647. https://doi.org/10.1080/14756366.2017.1284068

[14]. Veeresham, C. (2012). Natural Products Derived From Plants as a Source of Drugs. J. Adv. Pharm. Technol. Res., 3(4), 200-201. https://doi.org/10.4103/2231-4040.104709

[15]. Uddin, G., Rauf, A., Siddiqui, B.S., Muhammad, N., Khan, A., Shah, S.U.A. (2014). AntiNociceptive, Anti-Inflammatory and Sedative Activities of the Extracts and Chemical Constituents of Diospyros lotus L. Phytomedicine, 21(7), 954-959. https://doi.org/10.1016/j.phymed.2014.03.001

[16]. Gao, H., Cheng, N., Zhou, J., Wang, B., Deng, J.J., Cao, W. (2014). Antioxidant Activities and Phenolic Compounds of Date Plum Persimmon (Diospyros lotus L.) Fruits. J. Food Sci. Technol., 51(5), 950-956. https://doi.org/10.1007/s13197-011-0591-x

[17]. Ayaz, F.A., Kadioglu, A. (1999). Fatty Acid Compositional Changes in Developing Persimmon (Diospyros lotus L.) Fruit. New Zeal. J. Crop Hort., 27, 257-261. https://doi.org/10.1080/01140671.1999.9514104

[18]. Yildirim, N., Ercisli, S., Agar, G., Orhan, E., Hizarci, Y. (2010). Genetic Variation among Date Plum (Diospyros lotus) Genotypes in Turkey. Genet. Mol. Res., 9(2), 981-986.

[19]. Yılmaz, B., Genç, A., Çimen, B., İncesu, M., Yeşiloğlu, T. (2017). Characterization of Morphological Traits of Local and Global Persimmon Varieties and Genotypes Collected From Turkey. Turk. J. Agric. For., 41(2), 93-102. https://doi.org/10.3906/tar-1611-27

[20]. Loizzo, M.R., Said, A., Tundis, R., Hawas, U.W., Rashed, K., Menichini, F., Frega, N.G., Menichini, F. (2009). Antioxidant and Antiproliferative Activity of Diospyros lotus L. Extract and Isolated Compounds. Plant Food. Hum. Nutr., 64(4), 264-270. https://doi.org/10.1007/s11130-009-0133-0

[21]. Nabavi, S.M., Ebrahimzadeh, M.A., Nabavi, S.F., Fazelian, M., Eslami, B. (2009). In Vitro Antioxidant and Free Radical Scavenging Activity of Diospyros lotus and Pyrus boissieriana Growing in Iran. Pharmacogn. Mag., 5(18), 122-126.

[22]. Uddin, G., Rauf, A., Siddiqui, B.S., Shah, S.Q. (2011). Preliminary Comparative Phytochemical Screening of Diospyros lotus Stewart. Middle East J. Sci. Res., 10(1), 7881.

[23]. Moghaddam, A.H., Nabavi, S.M,. Nabavi, S.F., Bigdellou, R., Mohammadzadeh, S., Ebrahimzadeh, M.A., (2012). Antioxidant, Antihemolytic and Nephroprotective Activity of Aqueous Extract of Diospyros lotus seeds. Acta Pol. Pharm., 69, 687-692.

[24]. Rashed, K., Zhang, X.J., Luo, M.T., Zheng, Y.T., (2012). Anti-HIV-1 Activity of Phenolic Compounds Isolated From Diospyros lotus Fruits. Phytopharmacology, 3(2), 199-207.

[25]. Saral, S., Ozcelik, E., Cetin, A., Saral, O., Basak, N., Aydın, M., Ciftci, O. (2016). Protective Role of Diospyros lotus on Cisplatin-Induced Changes in Sperm Characteristics, Testicular Damage and Oxidative Stress in Rats. Andrologia, 48(3), 308317.

https://doi.org/10.1111/and.12448

[26]. Ayaz, F.A., Kadığlu, A., Hayırlığlu, S. (1995). Determination of Some Mono-and Disaccharides in The Fruits of Diospyros lotus L. Using Gas Chromatography. Turk. J. Bot., 19, 493-495. 
[27]. Ayaz, F.A., Kadığlu, A., Reunanen, M. (1997). Changes in Phenolic Acid Contents of Diospyros lotus L. During Fruit Development. J. Agr. Food. Chem., 45(7), 2539-2541. https://doi.org/10.1021/jf960741c

[28]. Ayaz, F.A., Kadığlu, A. (1998). Nonvolatile Acid Composition during Fruit Development of Diospyros lotus L. Turk. J. Bot., 22(2): 69-72.

[29]. Glew, R.H., Ayaz, F.A., Millson, M., Huang, H.S., Chuang, L.T., Sanz, C., Golding, J.B. (2005). Changes in Sugars, Acids and Fatty Acids in Naturally Parthenocarpic Date Plum Persimmon (Diospyros lotus L.) Fruit during Maturation and Ripening. Eur. Food Res. Technol., 221(1-2), 113-118. https://doi.org/10.1007/s00217-005-1201-9

[30]. Can, Z., Baltas, N. (2016). Bioactivity and Enzyme Inhibition Properties of Stevia rebaudiana. Curr. Enzym Inhib., 12(2), 188-194. https://doi.org/10.2174/157340801266 6160402001925

[31]. Cuendet, M., Hostettmann, K., Potterat, O., Dyatmiko, W. (1997). Iridoid Glucosides with Free Radical Scavenging Properties from Fagraea blumei. Helv. Chim. Acta, 80(4), 11441152 .

https://doi.org/10.1002/hlca.19970800411

[32]. Benzie, I.F.F., Strain, J.J. (1996). The Ferric Reducing Ability of Plasma (FRAP) as a Measure of "Antioxidant Power": The FRAP Assay. Anal. Biochem., 239(1), 70-76. https://doi.org/10.1006/abio.1996.0292

[33]. Apak, R., Güçlü, K., Özyürek, M., Karademir, S.E. (2004). Novel Total Antioxidant Capacity Index for Dietary Polyphenols and Vitamins C and E, Using Their Cupric Ion Reducing Capability in The Presence of Neocuproine: CUPRAC Method. J. Agr. Food Chem., 52(26), 7970-7981. https://doi.org/10.1021/jf048741x

[34]. Slinkard, K., Singleton, V.L., (1977). Total Phenol Analysis: Automation and Comparison with Manual Methods. Am. J. Enol. Viticult., 28(1), 49-55.

[35]. Yen, G.C., Duh, P.D., Tsai, H.L. (2002). Antioxidant and Pro-Oxidant Properties of Ascorbic Acid and Gallic Acid. Food Chem., 79(3), 307-313. https://doi.org/10.1016/S0308-8146(02)00145-0

[36]. Chanwitheesuk, A., Teerawutgulrag, A, Kilburn J.D., Rakariyatham, N. (2007). Antimicrobial Gallic Acid from Caesalpinia mimosoides Lamk. Food Chem., 100(3), 1044-1048. https://doi.org/10.1016/j.foodchem.2005.11.008

[37]. Samarghandian, S., Afshari, J.T., Davoodi S. (2011). Chrysin Reduces Proliferation and Induces Apoptosis in the Human Prostate Cancer Cell Line Pc-3. Clinics, 66(6), 10731079. https://doi.org/10.1590/S1807-59322011000600026

[38]. Mani, R, Natesan, V. (2018). Chrysin: Sources, Beneficial Pharmacological Activities, and Molecular Mechanism of Action. Phytochemistry, 145, 187-196. https://doi.org/10.1016/j.phytochem.2017.09.016

[39]. Salimi, A., Pourahmad, J. (2018). Role of Natural Compounds in Prevention and Treatment of Chronic Lymphocytic Leukemia. Polyphenols: Prevention and Treatment of Human Disease, 2nd ed.; Watson R.R., Preedy, V.R., Zibadi, S. Eds,; Academic Press: Cambridge, MA, USA, 2018, Volume 1-2, pp 195-203. ISBN: 9780128130094 